\title{
CARTESIUS: a group function based toolkit for hybrid molecular modelling
}

\author{
Mikhail Rudenko ${ }^{1 *}$, AL Tchougreeff ${ }^{1,2}$ \\ From 5th German Conference on Cheminformatics: 23. CIC-Workshop \\ Goslar, Germany. 8-10 November 2009
}

Modern methods of quantum chemistry have achieved significant successes. Nevertheless, modeling of certain classes of compounds remains problematic. The main complications are both high computational complexity of these methods and the lack of a unique way to determine the ground state with correct asymptotic properties for complex systems. One of the possible solutions is development of the hybrid molecular modeling methods.

Our approach to hybrid molecular modeling is based on the ideas of the group function approximation, first suggested by McWeeny [1] and further elaborated in [2]. This approximation lays a solid basis for simultaneous usage of most appropriate methods for computation of properties of each part of a complex system and consistent interpretation of the properties of the system independently of the methods used.

The CARTESIUS toolkit implements the above mentioned scheme in both flexible and computationally efficient way. This is achieved by means of combining cutting-edge $\mathrm{C}++$ techniques for computationally intensive parts of the code and the full power of Python for the control interface.

As a result we have a carefully designed software system, which possesses both the power of the quantum chemistry codes developed previously with use of the group function approximation (BF [3], EHCF [4], BFSCF [5] etc.) and high potential for further enhancements.

This work is partially supported by the RFBR through the grant No 07-03-01128.

Institute of Physics and Technology of RAS, Nakhimovsky ave. 36/1, 117218, Moscow; Moscow Center for Continuous Mathematical Education, 119991, Moscow, Russia

\section{Author details}

'Institute of Physics and Technology of RAS, Nakhimovsky ave. 36/1, 117218, Moscow; Moscow Center for Continuous Mathematical Education, 119991, Moscow, Russia. ${ }^{2}$ Aachen, Germany.

Published: 4 May 2010

\section{References}

1. McWeeny R: Methods of Molecular Quantum Mechanics Academic, London, 21992.

2. Tchougréeff AL: Hybrid Methods of Molecular Modeling Springer 2008.

3. Tokmachev M, Tchougréeff AL: J Phys Chem A 2003, 107:358.

Soudackov AV, Tchougréeff AL, Misurkin IA: Theor Chim Acta 1992, 83:389.

Tchougréeff AL, Tokmachev AM: Int J Quant Chem 2006, 106:571.

doi:10.1186/1758-2946-2-S1-P13

Cite this article as: Rudenko and Tchougreeff: CARTESIUS: a group function based toolkit for hybrid molecular modelling. Journal of Cheminformatics 2010 2(Suppl 1):P13. 